we were allowed two extra meat coupons per week. There was no effective treatment for the generalised oedema, and ascites became very severe and distressing. This could be treated only by paracentesis and this was done at frequent intervals. By the middle of 1943 there was gross generalised oedema, a hemiparesis had developed, and there was a chest infection.

He was seen then by the late Lord Evans-then Dr Horace Evans. Dr Evans advised that the only treatment which might help was a mercurial diuretic. He warned that this might have a fatal effect but that if it was not used the outlook would be very grave. And so $2 \mathrm{ml}$ of Mersalyl preceded by ammonium chloride was injected intramuscularly. The effect was dramatic. There was a tremendous diuresis and within $24 \mathrm{~h}$ from being grossly oedematous the patient became almost a skeleton. The hemiparesis also cleared up completely. The condition, however, did not clear up. The oedema recurred and over the next five years almost 300 injections of mercurial diuretics were given, usually once a week but sometimes twice, until in 1948 the symptoms all cleared up following tonsillectomy. Since then the patient has kept well and, in fact, spent 15 months in the Antarctic in 1960-1.

Had steroids been available in 1942 the treatment described in this case would never have been used, but the result confirms $\mathrm{Dr}$ Gabriel's point that proteinuria in itself is not injurious provided it is controlled by diuretics.

One interesting fact emerged during this illness. It was noticed that the intake of white meat always increased the urinary output. When we were able to obtain a chicken or a rabbit, although the fluid intake remained constant, the patient's urinary output always increased so that the intervals between the injections of diuretics could be prolonged.

J W M Humble

East Molesey, Surrey

\section{Prevention of vitamin D deficiency in the elderly}

SIR,-We read with interest the study of Dr W J MacLennan and Judith C Hamilton (1 October, p 859) on the effect of low-dose vitamin $\mathrm{D}$ supplements on serum 25 -hydroxy vitamin D (25-OHD) concentrations in elderly patients. As part of an assessment of the role of vitamin D-fortified foods in the prophylaxis of vitamin $\mathrm{D}$ deficiency in the elderly we carried out similar dose-response studies. Table I shows that in long-stay elderly hospital patients the equivalent of $10 \mathrm{~kg}$ of vitamin D daily for six months will produce significant increments in serum 25-OHD; correspondingly larger increments are produced with increasing dose levels. We agree with the authors that simple vitamin $\mathrm{D}$ deficiency in the elderly can be corrected by conventional prophylactic intakes of about $10 \mu \mathrm{g}$ of vitamin $\mathrm{D}$ daily. The efficacy of conversion to 1,25 dihydroxy vitamin $\mathrm{D}$ in the elderly remains to be assessed and may be important in the development of senile osteomalacia.

Since the regular administration of vitamin D supplements to large numbers of elderly patients may be difficult; enhancement of the ultraviolet (UV) component of ward lighting offers a potentially more reliable method of augmenting vitamin $\mathrm{D}$ intake. Vita-lite (Truelite in UK) fluorescent tubes (Duro-Test Corporation, New Jersey) have an emission spectrum similar to that of solar radiation. Neer $e t a l^{1}$ found that calcium absorption was significantly increased in elderly patients exposed to Vita-lite for eight hours at high

TABLE I-Response of serum 25-OHD concentration to a fortnightly vitamin D supplement given to longstay geriatric patients for six months

\begin{tabular}{|c|c|c|c|c|}
\hline \multirow[t]{2}{*}{ Vitamin D supplement (calciferol, $B P$ ) } & & \multicolumn{3}{|c|}{$\begin{array}{c}\text { Mean serum 25-OHD concentration (: } \\
(\mathrm{nmol} / 1)\end{array}$} \\
\hline & & Initial & Final & $P$ \\
\hline $\begin{array}{l}1.75 \mathrm{mg} \text { fortnightly } \approx 5000 \text { IU daily })(n=10) \\
350 \mu \mathrm{g} \text { fortnightly }(\approx 1000 \mathrm{IU} \text { (daily) }(\mathrm{n}=17) \ldots \\
140 \mu \mathrm{g} \text { fortnightly }(\approx 400 \text { IU daily) }(\mathrm{n}=75)\end{array}$ & $\begin{array}{l}\cdots \\
\cdots\end{array}$ & $\begin{array}{l}14.5 \cdot 1.05 \\
16.4: 1.25 \\
21 \cdot 1: 1.45\end{array}$ & $\begin{array}{l}93 \cdot 35: 11 \cdot 7 \\
40 \cdot 4: 2 \cdot 65 \\
34 \cdot 2: 3.6\end{array}$ & $\begin{array}{l}<0.001 \\
<0.001 \\
<0.001\end{array}$ \\
\hline
\end{tabular}

Conversion: SI to traditional units-25-OHD: $1 \mathrm{nmol} / 1 \approx 0.4 \mu \mathrm{g} / \mathrm{ml}$.

TABLE II-Ultraviolet irradiance of different sources of illumination (as measured by a portable spectral radiometer)

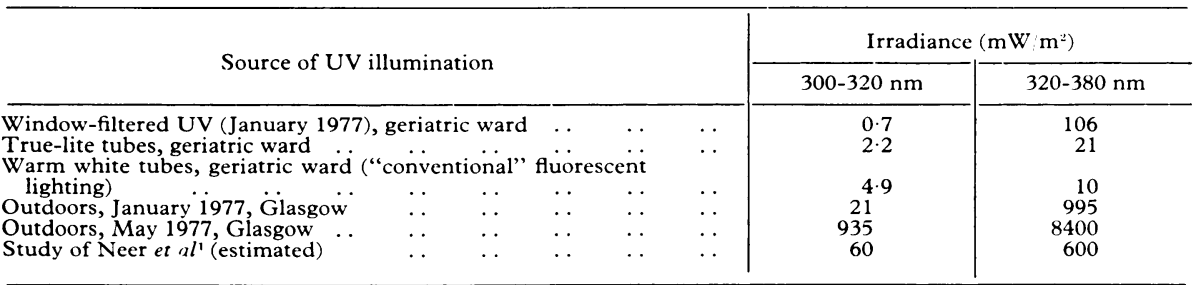

levels of illuminance $(538 \mathrm{~lx}$ (500 ft candles)), about 10 times that of normal room lighting in the USA. We have exposed eight elderly patients to True-lite tubes for 16 hours daily at normal hospital levels of illumination (16 $\mathrm{lx}$ (15 ft candles)). Over periods ranging from two weeks to six months (mean two months) levels of serum 25-OHD showed an insignificant mean rise ( $\pm \mathrm{SE}$ of mean) of $2 \cdot 25 \mathrm{nmol} / 1+2 \cdot 75(0.9 \pm 1 \cdot 1 \mathrm{ng} / \mathrm{ml})$. This result is perhaps not surprising when the measured spectral irradiance of the True-lite tubes at this level of illumination is compared with that of summer sunlight (table II). Indeed, norma warm white fluorescent tubes have about twice the irradiance in the antirachitic range (290-320 nm) at the same level of illumination. The intense illumination employed by Neer et al is impracticable in a geriatric ward and there is some evidence, ${ }^{2}$ albeit in pigeons, tha high levels of fluorescent illumination may cause retinal damage. We are undertaking further studies with normal lighting supplemented by UV irradiation in the $280-320 \mathrm{~nm}$ range within maximum permitted exposure limits.

Department of Clinical Physics and Bioengineering, Glasgow

J CONELY D SUMNER

National Radiological Protection Board, Scottish Centre, Glasgow

A McKinlay

W McINTOSH M G DUNNIGAN

Department of Biochemistry and

Division of Medicine,

Stobhill General Hospital, Glasgow

'Neer, R, et al, Nature, 1971, 229, 255 14, 164.
Marshall, et al, Experimental Eye Research, 1972,

\section{Incidence and mortality of acute pancreatitis}

SIR,-Mr M J McMahon (19 November, p 1350) comments on the incidence of acute pancreatitis and reports an incidence for Leeds of 110 cases per million population for the year 1976. The incidence in the Notting- ham defined population ${ }^{1}$ area, when diagnostic criteria similar to those used in Leeds are employed, varied fivefold during the eight years 1969-76 from a peak incidence of $100 \cdot 0$ per million population in 1975 to a low incidence of 21.2 per million in 1970. Assessment of severity of the disease suggests that more of the same spectrum of the disease is seen rather than an excess of mild cases in high-incidence years and a deficiency in low-incidence years. It may be that similar fluctuations occur in Leeds, as Trapnell and Duncan" recorded similar variations in Bristol. However, the mean incidence of 53.8 per million for Bristol for 1961-7 is of a similar order to the mean incidence of 56.9 per million for the Nottingham defined population area for the period 1969-76. A longer period of study in Leeds may produce different results.

I agree with $\mathrm{Mr} \mathrm{C}$ W Imrie's comments (19 November, p 1350) that care should be taken in extrapolating from regional surveys to national statistics, and he has well pointed out that Glasgow has a high incidence of acute pancreatitis. ${ }^{3}$ However, I cannot agree with his comments about mortality. The mortality from any disease is made up from those in whom the diagnosis is made in life and those in whom the diagnosis is made only at necropsy. In the total Nottingham series during the period 1969-76 (see table) the overall mortality was $16.3 \%$. However, these

Diagnosis in life and at necropsy and mortality in primary acute pancreatitis in the total Nottingham series, $1969-76^{1}(n=332)$

Diagnosis made in life

Diagnosis made at necropsy

Mortality when diagnosis made in life

$310(93 \cdot 4 ")$

$22\left(6.6{ }^{\prime \prime}\right)$ $32(10 \cdot 3 " . ")$
$54\left(16 \cdot 3^{\prime \prime . .1}\right)$

figures deserve closer analysis. In the total series the diagnosis was made only at necropsy in 22 cases $(6.6 \%)$ and careful analysis of the medical records showed that the clinicians caring for the patient did not suspect the diagnosis during life. This group was characterised by being unwell at home for typically more than three days before admission to hospital. If only the patients in whom the diagnosis was made during life are considered, and these are the patients who may be assumed to have had adequate management, the mortality was $10.3 \%$. In Pollock's series of 100 patients with acute pancreatitis ${ }^{4}$ nine were 